\title{
LeOnardo Sciascia e a Verdade IMPRONUNCIÁVEL
}

\section{Leonardo Sciascia e la Verità Impronunciabile}

\section{Leonardo Sciascia and the Unpronunciable Truth}

\author{
Gisele Palmieri*
}

RESUMO: O presente artigo investiga as considerações do escritor siciliano Leonardo Sciascia a respeito da omertà, a "lei do silêncio". A prática está, em sua origem, ligada ao modus operandi da malavita meridionale, embora também seja considerada um hábito cultural da sociedade siciliana. Encontramos críticas à omertà tanto em ensaios quanto em alguns romances do autor, como Il giorno della civetta (1961), A ciascuno il suo (1967) e Il contesto (1971). Tal crítica, que se apresenta de modo latente nos textos literários, pode indicar que essa prática foi uma importante preocupação de Sciascia, embora tenha sido escassamente abordada em estudos sobre a sua obra. Acredita-se que o fato de o intelectual ser lembrado como o primeiro a abordar a máfia na literatura, de maneira não folclórica, associado à ausência de qualquer menção à palavra omertà nos romances citados, acabou por desviar o foco do silêncio vinculado à máfia, presente sutilmente em suas obras literárias. Para Sciascia, a prática da omertà, além de garantir a impunidade da máfia, colocava o siciliano na incômoda posição de protetor dos mafiosos. Sendo assim, consideramos ser o silêncio sobre a máfia (e não o silêncio da máfia) a maior acusação feita pelo escritor à sociedade siciliana.

PALAVRAS-CHAVE: Sicília; máfia; omertà.

ABSTRACT: Il presente articolo indaga le considerazioni dello scrittore siciliano Leonardo Sciascia sull'omertà, la "legge del silenzio". La pratica è, in origine, legata al modus operandi della malavita meridionale, sebbene sia considerata anche un'abitudine culturale della società siciliana. Troviamo critiche all'omertà sia nei saggi che in alcuni romanzi dell'autore, come Il giorno della civetta (1961), A ciascuno il suo (1967) e Il contesto (1971). Tale critica, che viene presentata in modo latente nei testi letterari, può indicare che questa pratica era una preoccupazione importante di Sciascia, sebbene

\footnotetext{
*Universidade Federal do Rio de Janeiro (UFRJ)

gmnp80@yahoo.com.br - (ORCID: 0000-0002-1616-9842)

DOI: http://dx.doi.org/10.11606/issn.2238-8281.v0i41p69-83
} 
sia stata scarsamente affrontata negli studi della sua opera. Si ritiene che il fatto che l'intellettuale sia ricordato come il primo ad avvicinarsi alla mafia nella letteratura, in modo non folclorico, associato all'assenza di qualsiasi menzione della parola omertà nei predetti romanzi, abbia finito per distogliere l'attenzione dal silenzio legato alla mafia, sottilmente presente nelle sue opere letterari. Per Sciascia la pratica dell'omertà, oltre a consentire alla mafia di operare impunemente, poneva il siciliano nella scomoda posizione di protettore dei mafiosi. Pertanto, riteniamo che il silenzio sulla mafia (e non il silenzio della mafia) sia la più grande accusa rivolta dallo scrittore alla sua società.

PAROLE CHIAVE: Sicilia; mafia; omertà.

ABSTRACT: This study investigates the considerations from the Sicilian author Leonardo Sciascia regarding omertà, the "law of silence." From its inception, the practice has been linked to the modus operandi of malavita in meridional Italy, although it is also considered a cultural standard in Sicilian society. We found criticism to omertà both on the author's essays and in some of his novels, such as Il giorno della civetta (1961), A ciascuno il suo (1967) e Il contesto (1971). These criticism, which is presented latently in the literary texts, may indicate that this social convention was a relevant concern to Sciascia, despite rarely being addressed in studies about his work. The subtle focus on his oeuvre on this silence involving the mafia appears to have been diverted away. It is believed to be due to the intellectual being regarded as the first to narrate mafia in literature in a non-folkloric way, and the absence of any mention to the word omertà in his novels. To Sciascia, the practice of omertà, in addition to serving as a means to ensure that the mafia will enjoy impunity, also places Sicilians as mafia defenders, which is an uncomfortable position. Thus, we consider the silence about mafia (as opposed to the silence of mafia) to be the writer's most significant accusation of Sicilian society.

KEYWORDS: Sicily; mafia; omertà 


\section{Uma nova denúncia?}

Denunciar a máfia é uma atividade comumente atribuída ao escritor e intelectual Leonardo Sciascia (1921-1989), nascido em Racalmuto, comuna italiana da região da Sicília, tornando-se, assim, sua grande marca no cenário literário italiano. É notório que o romance Il giorno della civetta (1961) foi o primeiro a representar a máfia de forma não apologética, maneira com a qual o tema vinha sendo apresentado na literatura até a publicação desse romance. $\mathrm{Na}$ sequência desse primeiro giallo vêm os romances A ciascuno il suo (1967) e Il contesto (1971), considerados, juntamente com Il giorno della civetta, “(...) una trilogia di gialli, per caratterizzare meglio la mafiosità del potere.” (PULEIO, 2003, p. 61).

Nas obras literárias em análise, Leonardo Sciascia constrói enunciadores que praticam a lei do silêncio, uma regra da máfia siciliana conhecida como omertà. Considerando-se o contexto histórico em que o escritor publicou seus romances e seus ensaios, convém saber que a máfia, na década de 1950 e 1960, era um assunto incômodo dentro da sociedade italiana. Ou negava-se a questão ou ela era tratada sem a devida importância que sua complexidade exigia. Esse fato desagradava Sciascia, de maneira que ele se propôs a escrever sobre a máfia sem os costumeiros véus de indiferença de que outros escritores se utilizaram, a ponto de o escritor siciliano ser reconhecido como o primeiro a mostrá-la de maneira não folclórica, em representações literárias.

A omertà, lei do silêncio que atua como um dos princípios de bom funcionamento da máfia seria, também, uma prática cultural dos sicilianos, fruto de características identitárias, que neste trabalho identificamos como sicilitudine. Segundo apontam alguns estudos sobre a máfia, tal organização criminosa teria se apropriado da prática cultural de se fazer justiça de maneira extralegal, sem a necessidade de intervenção do Estado - comportamento considerado típico dos sicilianos ou meridionais - ressignificando essa prática ao contexto do grupo. Porém, Leonardo Sciascia apresenta uma interpretação diferente quando não acredita em uma instrumentalização da omertà pela máfia, lendo-a como um traço identitário, um "modo de ser" característico da Sicília, incluindo o comportamento dos integrantes da máfia dentro dessa explicação.

Levantaremos as principais considerações feitas por Leonardo Sciascia a respeito da omertà, em comparação com as considerações de outros intelectuais e escritores. Interessa-nos, neste trabalho, a leitura que Sciascia faz sobre a lei do silêncio no território siciliano e as razões, apresentadas por ele, que justifiquem esse hábito na Sicília. O objetivo é mostrar que a peculiar opinião de Sciascia sobre o assunto, encontrada em seus ensaios, ganha representação em seus romances policiais, classificados, também, como romances-ensaio, posto que neles identificamos o mesmo conteúdo do seu material ensaístico. No âmbito da temática mafiosa, acreditamos ser a questão do silêncio sobre a máfia o cerne da discussão proposta por Sciascia, de maneira implícita, nos romances que compõem o corpus desta pesquisa. 


\section{As diversas concepções e interpretações de omertà}

Segundo o dicionário Treccani, originalmente, o verbete "omertà" - variante napolitana de umiltà (humildade) - é, no contexto do Sul da Itália, uma lei de silêncio que consiste em se manter sigilo sobre o nome do autor de um delito, a fim de que o crime não se resolva pelas leis do Estado, mas pela vingança do ofendido, um costume vigente na malavita meridionale (camorra e mafia). Mais genericamente, no uso atual, consiste em um princípio de solidariedade visando a ocultação da identidade do autor de um crime. Essa "solidariedade" é motivada por interesses próprios ou medo de represálias, fazendo quem se solidariza abster-se de acusações, denúncias, depoimentos ou mesmo julgamentos contra qualquer pessoa ou situação. Outra definição dada pelo mesmo dicionário, ${ }^{2}$ tendo como referência a Enciclopedia Italiana (1935), de Raffaele Corso, indica ser a "omertà" uma palavra siciliana a qual consiste em uma lei isolana, não escrita, que obrigava o cidadão a não revelar o nome do infrator e a não denunciá-lo, deixando o ato de vingança estritamente para o ofendido: uma espécie de código de honra que induz os envolvidos a resolverem disputas utilizando seus próprios recursos, ou seja, por meios contrários à lei do Estado. Aqueles que descumprissem tal regra, além de possíveis represálias, seriam condenados pela opinião pública e considerados infames. Para o World Book Dictionary, omertà significa um código de honra siciliano que proíbe informar sobre crimes que sejam considerados negócios pessoais dos envolvidos (PUZO, 2000, p. 7).

A prática, segundo Lupo (2002), tem origem nas regras de iniciação maçônica:

Nas organizações maçônicas oitocentistas, mesmo fora da Sicília, o delator é chamado de infame. Do conceito maçônico de humanidade deriva o conceito camorrístico de humildade, vale dizer, subordinação à vontade da organização; desta umiltà, pela conversão do 1 em r, típica do dialeto siciliano, viria a palavra omertà (...) (LUPO, 2002, p. 53)

Embora o comportamento tenha origem maçônica e o conceito tenha origem napolitana, o termo foi cunhado pelo dialeto siciliano. A omertà, assim entendida, não é um hábito exclusivamente siciliano, como visto em algumas das definições dadas ao termo. Considerada, originalmente, uma prática da malavita do Meridione $e^{3}$ italiano, a lei do silêncio, além de ser uma regra de iniciação da Camorra (organização criminosa napolitana) e da 'Ndrangheta (organização criminosa calabresa), também é um hábito da sociedade daquelas regiões (Nápoles e Calábria). Leonardo Sciascia aponta que todas as organizações criminosas possuem uma rede protetiva em seu entorno: "Tutte le associazioni segrete che - quale ne sia il fine - usano il crimine come mezzo, si somigliano non solo nella struttura organizativa e gerarchica, ma anche nella ricerca ed espansione, intorno a sé, di un constesto silenzioso, omertoso e di protezione" (SCIASCIA, 2017, p. 25). O hábito do silêncio omertoso não é exclusivamente siciliano, portanto. Daremos enfoque, entretanto, às considerações feitas pelo escritor Leonardo Sciascia a respeito da prática da omertà, especificamente, na Sicília.

1 Disponível em: <http://www.treccani.it/vocabolario/omerta/>. Acesso em: 10/01/2019.

2 Disponível em: <http://www.treccani.it/enciclopedia/omerta_\%28Enciclopedia-Italiana\%29/>. Acesso em: 18/08/2020.

3 O termo Meridione, neste artigo, é utilizado como sinônimo de Mezzogiorno, macrorregião que compreende a Itália meridional e a insular. 
O mestre de Racalmuto faz muitas considerações a respeito da omertà siciliana em vários de seus ensaios dedicados à temática da máfia. Em alguns, acusa a impotência das forças armadas sicilianas, que ficam sem possibilidade de ação pela prática desta lei do silêncio:

(...) la polizia, di fronte a un qualsiasi reato, è nelle identiche condizioni di un qualunque privato cittadino: ha davanti il muro del silenzio, dell'omertà; non possiede attrezzatura scientifica; non possiede ora nemmeno la risorsa (discutibilissima risorsa) di dilatare a volontà i termini 'del fermo'. Privata del 'confidente', i compiti della polizia resterebbero limitati ai soli delitti cosidetti passionali (si pensi che non ho mai visto in Sicilia la polizia effetuare rilievi dattiloscopici in delitti in cui la scoperta di una sola impronta digitale sarebbe stata forse risolutiva) (SCIASCIA, 1996, p. 207, grifo do autor)

O escritor evidencia os crimes de máfia como aqueles cuja investigação policial será sempre inconclusa, posto que a organização criminosa possui em seu entorno uma rede colaborativa, protetiva, que impossibilita a justa aplicação das leis punitivas:

(...) tutti i delitti 'oscuri', in cui l'identificazione del colpevole è difficile se non addiritura impossibile, sono compiuti, o almeno avallati, dalla mafia. Questi godono di una rete protetiva - omertà, alibi e garanzie economiche - quasi inestricabile; mentre altri delitti restano, nel senso proprio della parola, scoperti (SCIASCIA, 1996, p. 205, grifo do autor)

Essa rede protetiva à qual se refere Sciascia, que ergue o "muro do silêncio" diante das leis e da ordem pública de segurança, é composta não apenas pelos próprios mafiosos que formam cada $\operatorname{cosc} a^{4}$ da região da Sicília. Eis aqui a diferença entre o tessuto prottettivo que envolve a máfia e o que envolve outras organizações secretas:

Nel fenomeno mafioso, cui di solito si fa richiamo a paragonare da ogni altra associazione segreta criminale, il tessuto prottettivo che lo circunda è così durevole e tenace, che la paura finisce con l'apparire elemento secondario. Se poi si tiene presente che la mafia non è mai stata considerata - se non dal fascismo - come fatto eversivo dell'ordine costituito ma piuttosto come sistema parallelo e speculare rispetto all'altro e con l'altro connivente o addirittura integrato, le ragioni della protezione che un'intera società più o meno consapevolmente le accorda appaiono del tutto evidente. (SCIASCIA, 2017, p. 25, grifo do autor)

Percebe-se que ele exclui a hipótese da prática da omertà motivada pelo medo ou ainda por envolvimento com a organização criminosa e acusa a "sociedade inteira" de realizar esta proteção à máfia.

Muitas décadas antes de Sciascia, Giuseppe Pitrè (1841 -1916) defende uma das interpretações mais criticadas por outros estudiosos sobre a máfia e a omertà. Na publicação Usi e

4 còsca s. f. [voce sicil., che risale al lat. tardo cŏstŭla «costola»; propr. «costola della foglia», quindi la foglia stessa, o un insieme di foglie]. - Nucleo, aggruppamento di mafiosi della Sicilia, che, agli ordini di un capo (il cosiddetto «pezzo da novanta»), svolge la sua attività criminosa, di sfruttamento e di sopraffazione in una zona e in un settore determinati(...). Disponível em: <http://www.treccani.it/vocabolario/cosca/>. Acesso em: 17/08/2020. 
costumi, credenze e pregiudizi del popolo siciliano (1870) o etnólogo italiano coloca o homem mafioso como altivo e valente, o que explicaria o repúdio deste à intervenção do Estado em suas desavenças pessoais, um traço de valentia e não prepotência. Para o etnólogo siciliano:

Il mafioso vuol essere rispettato e rispetta quasi sempre. Se è offeso non ricorre alla Giustizia, non si rimette alla Legge; se lo facesse, darebbe prova di debolezza, e offenderebbe l'omertà, che ritiene schifiusu, o 'nfami chi per aver ragione si richiama al magistrato." (PITRÈ, 1940, p.295)

Pitrè considera que recorrer à justiça e quebrar o pacto da omertà seria, então, um desrespeito, posto que, em seu juízo, silenciar sobre assuntos que envolvem o "mafioso" é uma virtude. Contemporâneo de Pitrè, o economista e político italiano Leopoldo Franchetti (1847-1917) rebate a ideia, difusa naquela época, de que o mafioso era um homem corajoso e respeitoso e a omertà uma regra de virtude e honra e, assim como Sciascia, também interpreta a lei do silêncio como uma prática maléfica para a sociedade, porém, diferentemente do escritor siciliano, o escritor toscano defendeu a ideia do ato de silenciar como uma imposição destes grupos criminosos à sociedade:

Ora, l'interesse della classe dei facinorosi per mestiere essendosi ormai imposto come il più forte di ogni altro alla Società in Palermo e dintorni, ne è risultato il fatto di cui già ragionammo, che, cioè, questo interesse si è imposto agli animi, all'opinione pubblica insomma, come interesse dell'intera società, e così, le regole che si sono imposte agli animi della popolazione come regole di virtù, di moralità e di onore, sono quelle che favoriscono l'esistenza di codesta classe. Vogliamo parlare di quell'assieme di norme in virtù delle quali è proibito ricorrere alla legge contro la violenza, pena non solo la morte ma anche il disonore. Queste regole sotto il nome di codice dell'omertà sono in Palermo e dintorni più che nel rimanente di Sicilia precise e stringenti nella popolazione, perché qui l'interesse che colla forza si è imposto materialmente e moralmente è quello di una classe intera, [...] (FRANCHETTI, 1877, p. V, grifo do autor)

Para Franchetti, a autoridade moral da lei do silêncio se explicaria pela essência violenta dos sicilianos de Palermo e arredores, além da noção de impessoalidade da lei que os mafiosos compartilham com a população siciliana. "Os sicilianos parecem demasiado briguentos, facciosos, tendentes a administrar de maneira privatista a coisa pública.”, aponta Lupo (2002:16) referindo-se à ideia vigente na época de Franchetti, considerada como uma versão da máfia enquanto "metáfora do atraso" da Sicília em relação ao restante do país.

A visão de Sciascia se aproxima da visão apresentada por Franchetti, que foi o primeiro a apontar um "comportamento mafioso" na população siciliana. Embora Franchetti e Sciascia concordem em considerar a essência mafiosa da sociedade siciliana como um todo, o enfoque dado à questão da omertà, no primeiro, recai no silêncio enquanto regra de máfia, imposta a uma sociedade coagida a recebê-la, e não enquanto um desinteresse do siciliano em se envolver 
em assuntos alheios a sua esfera particular e familiar, um silêncio autoimposto como condição existencial, conforme o segundo. Se a leitura do economista e escritor toscano versa sobre o silêncio de maneira bifurcada, em que há o código da omertà como costume da máfia imposto à população, Sciascia inverte a lógica e considera que a lei do silêncio, tanto como modus operandi da organização criminosa quanto como prática social, desemboca em uma manifestação do "modo de ser" daquela coletividade.

$\mathrm{Na}$ contemporaneidade, uma opinião sobre a omertà, mais próxima àquelas dadas por Leonardo Sciascia, encontramos em Roberto Saviano (1979). De acordo com o escritor napolitano, "l'omertà non è solo non denunciare un reato che vedi coi tuoi occhi, ma è soprattutto non voler sapere, capire, conoscere". (LORUSSO, 2010) A definição de Saviano sobre a prática da lei do silêncio que circunda os crimes da malavita meridionale vem ao encontro da reflexão feita por Sciascia que, décadas antes do jornalista autor de Gomorra (2006), já denunciava que o silêncio sobre a máfia, na região da Sicília, é proveniente da indiferença e da apatia do siciliano, um problema cujas raízes, no caso as sicilianas, encontram-se na configuração cultural e identitária da região. Sciascia busca não apenas apontar o "comportamento mafioso" dessa sociedade, conforme Franchetti já havia apontado em 1876 em Condizioni politiche e amministrative della Sicilia, mas também busca explicar as razões que levam o siciliano a praticar a omertà sem percebê-la como uma imposição externa, e não por medo de coação ou por contiguidade violenta.

Enquanto para os estudiosos predecessores de Sciascia a omertà na Sicília se configura ou como uma imposição à sociedade de uma regra da máfia ou como um ato de virtude, para Sciascia a sociedade siciliana sequer a reconhece como uma imposição, posto que não interpreta a máfia como uma subversão à ordem pública. "Tanto più una società si riconosce nelle leggi che le associazioni segrete vogliono ignorare o abbattere, e se ne sente garantita, tanto meno diffuso sarà, intorno al raggruppamento clandestino, il contesto direttamente o indirettamente protettivo." (SCIASCIA, 2017, p. 25). O alcance da rede de proteção à máfia, de acordo com o escritor, é proporcional ao não reconhecimento dos sicilianos das leis oficiais que os regem.

A partir deste ponto será necessário fazermos observações a respeito das características identitárias dos habitantes da ilha, consideradas, por Sciascia, a base da prática da omertà . O objetivo é tentarmos buscar as possíveis raízes da lei do silêncio praticada pela sociedade siciliana e pela máfia, de forma a embasarmos a visão do escritor racalmutese sobre o assunto.

\section{Omertà: uma questão de identidade?}

Os sicilianos possuem, dentro da configuração da nação italiana, características culturais peculiares, denominadas sicilianità ou sicilitudine. Cabe uma diferenciação entre os dois termos: "Enquanto sicilianità determina o siciliano como um ser, sicilitudine é uma manifestação da personalidade daquele ser. A sicilitudine evoca a solitude e o hermetismo do siciliano". 
(BARNI e BONA, 2016, p. 162-165). Leonardo Sciascia aborda a sicilitudine em seus textos, debatendo a questão da insularità $:^{5}$

Si può dunque dire che l'insicurezza è la componente primaria della storia siciliana; e condiziona il comportamento, il modo di essere, la visione della vita - paura, apprensione, diffidenza, chiuse passioni, incapacità di stabilire rapporti al di fuori degli

affetti, violenza, pessimismo, fatalismo, - della collettività e dei singoli (SCIASCIA, 2016, p. 10)

Essa insegurança de que fala Sciascia é causada pelas constantes invasões - de diferentes povos - sofridas pela ilha, dada a sua posição geográfica, o que teria condicionado o "modo de ser" do siciliano, segundo a tese sciasciana. "La paura storica é diventata paura esistenziale (SCIASCIA, 2016, p. 10). Ele esclarece que em Il giorno della civetta a sicilitudine é representada por "quello che partecipa all'associazione mafiosa e coloro che la proteggono uomini politici o funzionari dello Stato.” (BALDWIN, 1998, p. 117). Do que se conclui que o hábito do silêncio seria um dos componentes da sicilitudine, enquanto "modo de ser", comportamento identitário tanto por parte dos mafiosos quanto por parte da sociedade que os protege.

A explicação que Sciascia encontra para o comportamento da omertà - que, segundo sua análise, é causado pelo isolamento, um problema deste homem isolano - é, conforme demonstramos, de base histórica. A sicilitudine como consequência histórica, portanto, será utilizada pelo autor como um álibi para explicar o hábito do silêncio praticado pelo siciliano, diante dos crimes de autoria mafiosa e diante da corrupção do poder público.

Em uma entrevista dada à jornalista francesa Marcelle Padovani e publicada em La Sicilia come metafora (1979), o escritor racalmutese defende que uma das raízes da máfia é um comportamento proveniente da própria instituição familiar siciliana: "In Sicilia la famiglia, nelle sue vaste ramificazioni, ha questa funzione: di proteggere, di privilegiare i suoi membri rispetto ai doveri che la società e lo Stato impongono a tutti. È la prima radice della mafia, lo so bene". (SCIASCIA, 1979, p. 7). Para Sciascia, encontra-se nesse fato o embrião do dito "comportamento mafioso" siciliano. Ele apresenta o "familismo" como o cerne da questão da proteção contra os deveres sociais e contra a subserviência às leis, vendo uma ligação entre este aspecto identitário e o surgimento daquele fenômeno social. Nesta leitura, percebemos que, de certa forma, ele atribui uma parcela de responsabilidade pelo surgimento da máfia à configuração familiar siciliana.

O escritor afirma categoricamente que, em geral, não é o medo, fruto de uma imposição, o motivo pelo qual os sicilianos praticam a lei do silêncio, mas a noção, consciente ou inconsciente, por parte da sociedade, de que a máfia é o Estado. Ele explica melhor esse fato em parte da entrevista, quando rememora um episódio ocorrido no enterro de um mafioso, na província de Caltanisseta. Quase toda a população local comparece ao funeral para homenagear o morto.

5 Insularità: "Il sentimento della propria origine isolana, in quanto è avvertito da chi vive in un'isola o in quanto si riflette con particolari caratteri nell'opera, soprattutto narrativa, di uno scrittore e negli atteggiamenti psicologici e morali dei suoi personaggi: tutte queste cose hanno formato il carattere nostro, che così rimane condizionato da fatalità esteriori oltre che da una terrificante i. d'animo" (Tomasi di Lampedusa). Disponível em: <http://www. treccani.it/vocabolario/insularita/>. Acesso em: 29/07/2020. 
Observados pela polícia, nenhum cidadão presente ao evento parece se preocupar ou se incomodar com a chegada das autoridades enquanto estão prestando condolências ao criminoso. "Il comportamento della popolazione di Riesi può avere questa sola spiegazione: il carabiniere, lo Stato, la legge dello Stato erano come inesistenti di fronte a quei funerali, come se non ci fossero."(SCIASCIA, 1979, p. 31-32). Sciascia atribui tal comportamento ao desconhecimento, por parte da sociedade, de quem representava o poder legal. Para o siciliano, a máfia é o seu governo. Ficam claros, nessas passagens da entrevista dada a Marcelle Padovani, que Sciascia evoca traços de sicilitudine como a "recusa do conceito de impessoalidade da lei, desprezo pela polícia e por quem colabora com ela [...]" para tentar explicar o comportamento de indiferença dos sicilianos em relação à existência de uma organização criminosa na região. (LUPO, 2002, p. 26).

Sciascia refuta a imagem do siciliano cúmplice da máfia, posto que sequer a percebe como subversão da lei: “Credevo anch'io, che nella mafia, nel 'sentire mafioso', nell'indifferenza della maggior parte dei siciliani di fronte alla mafia, (...) semplicemente si tratta di un 'modo d'essere"” (SCIASCIA, 2017, p. 102). Estaria aí a motivação da prática do silêncio na Sicília, com relação às atividades mafiosas: “(...) il non voler giudicare uomini da cui credono di non aver ricevuto alcun danno." (SCIASCIA, 2017, p. 102). Salvatore Lupo (1951-) considera inadequada a ideia de que a máfia seja uma consequência daquilo que ele chama de "antropologia do siciliano". Para o historiador e professor universitário toscano, "seria preciso tentar separar o fenômeno do seu contexto, indagando sobre o modo pelo qual a organização mafiosa se apropria dos códigos culturais, instrumentaliza-os, modifica-os, tornando-os um adesivo para sua estrutura" (LUPO, 2002, p. 26). Para o escritor, no entanto, separar o fenômeno de seu contexto revela-se impossível. "Il mafioso - come ha dimostrato Henner Hess - non sa di essere mafioso, vive nella mafia come nella propria pelle. Vive dentro una cosa che 'c'è.", defende Sciascia (2017, p. 26). O "sentire mafioso" faz parte da cultura do siciliano, de uma visão de vida, parece concluir. Ressalta-se, porém, que ser "mafioso" e ser "integrante da máfia", para Sciascia, são lidos como fatos distintos. Defende o escritor que a máfia é uma organização, pois "si tratta di un'atmosfera che spara e che, per di più, spara in determinate direzioni." (SCIASCIA,1996, p.193). Sabemos de seu notável trabalho - enquanto intelectual - de denúncia da existência de uma associação criminosa na Sicília. Mas a tal "essência mafiosa" que atribui aos sicilianos, independentemente de serem integrantes da máfia ou não, relaciona-se às características identitárias dessa sociedade. Uma vez que a identidade siciliana é assimilada à identidade dos criminosos-mafiosos da região, estereotipa-se o comportamento isolano conforme o grupo que tornou famoso esse "modo de ser". Assim, todos serão vistos como mafiosos, posto que se comportam da mesma maneira, por isso Sciascia acusa a máfia, mas não o mafioso, conforme pudemos constatar. Por fim, para o escritor racamultese não há, em princípio, como acusar os sicilianos de serem coniventes com a máfia, pois nem mesmo o mafioso se reconheceria como tal. Exime a sociedade dessa culpa, apontando, contudo, para os efeitos da sicilitudine, que ele vê de maneira negativa. 
Seu trabalho de intelectual será mostrar que, embora o silêncio mediante as ações da máfia seja apenas uma falta de reconhecimento da fenomenologia mafiosa como subversão à lei, e não uma demonstração de conivência, a prática da omertà tem consequências drásticas para a sociedade. Lida por Sciascia como um indicador de apatia, indiferença e submissão diante da máfia e da corrupção do poder público, a prática alimenta o poder da máfia e, consequentemente, a mafiosità del potere. O homem isolano, ${ }^{6}$ que vive em uma sociedade imutável, "por sua tradicional impermeabilidade ao novo" (LAMPEDUSA, 2007, p. 184) e com "l'idea che, per essere completamente se stessi, bisogna esser soli, (...) (SCIASCIA, 1979, p. 46), não se preocupa com os acontecimentos sociais e históricos à sua volta. "Un solo difetto in tutto questo, ed è che quando si è soli si è fatalmente d'accordo col mondo, e che non si pensa affatto a trasformarlo, a migliorarlo o a distruggerlo. Lo si accetta qual è!” (SCIASCIA, 1970, p. 46). A omertà, um dos elementos identitários que compõem a sicilitudine, aparece, então, como um silêncio existencial, e não instrumentalizado. Por fim, entendemos que Sciascia não julga as causas da sicilitudine, mas julga as consequências.

É perceptível em seus escritos a ideia de que os mecanismos utilizados pela organização criminosa têm como base formadora e mantenedora os aspectos culturais da identidade siciliana, porém ele não faz, como Lupo, uma separação entre o fenômeno mafioso e o seu contexto. Embora em seus ensaios ele demonstre incomodar-se com a acusação de cumplicidade entre a sociedade e os mafiosos propriamente ditos, não exime os sicilianos dessa responsabilidade. Acreditamos que aquilo que mais chama sua atenção não seja a lei do silêncio enquanto regra interna da máfia, enfim, o silêncio da máfia, mas sim, o silêncio sobre a máfia. É necessário, para Sciascia, apresentar as consequências da prática da omertà, pois silenciar sobre a existência de uma organização criminosa acaba sendo a causa do imobilismo social da Sicília. E também, a causa da corrupção e da impunidade existentes na classe política da região.

\section{Indícios da omertà no texto literário sciasciano}

Para Leonardo Sciascia, o que distingue a "verdadeira literatura" da "falsa literatura" é o inefável senso da verdade. Esta é a função que o autor atribui à sua atividade literária: falar a verdade. Ele defende que "lo scrittore sia un uomo che vive e fa vivere la verità, che estrae dal complesso il semplice, che sdoppia e raddoppia - per sé e per gli altri - il piacere di vivere. Anche quando rappresenta terribili cose." (SCIASCIA, 1979, p. 78). A escolha por representar as "coisas terríveis" da Sicília rendeu-lhe o epíteto de "escritor pessimista".

Sciascia posiciona-se, com frequência, contra a máfia e todas as formas de poder e faz de seus romances (pseudo) policiais, pamphlets. A literatura, para ele, torna-se um dos meios de manifestação política, social e identitária. Sciascia "considerava i risultati letterari 'assolutamente secondari' alle idee.” (FRANCESE, 2012, XII). Ao apresentar uma visão menos fanta-

6 Iśolano agg. [dal lat. insulanus, der. di insŭla «isola»]. - Di un'isola (e s'intende per lo più di una particolare isola): prodotti i.; la gioventù i.; riferito a persona e sostantivato, nativo o abitante dell'isola: gli i. della Sardegna, della Sicilia; turisti che familiarizzano con gli isolani. Con senso più generico, si usa insulare. Disponível em: <http://www.treccani.it/vocabolario/isolano/>. Acesso em: 22/08/2020. 
siosa da máfia, sem o seu habitual aspecto folclórico, renuncia a uma representação romântica da ilha e dos mafiosos, em detrimento da denúncia social, a qual evoca uma imagem menos atraente de sua região.

O escritor racamultese ultrapassa o muro da omertà ao propor-se a romper o silêncio sobre a organização criminosa, representando-a conforme era, de fato, em sua época. Fazendo isso, ele vence a omertà autoimposta por sua "essência mafiosa". "Quando denuncio la mafia, nello stesso tempo soffro poiché in me, come in qualsiasi siciliano, continuano a essere presenti e vitali i residui del sentire mafioso. Così, lottando contro la mafia io lotto anche contro me stesso, è come una scissione, una lacerazione." (SCIASCIA, 1979, p. 74), relata o escritor ao revelar sua resistência à secular passividade existencial siciliana.

Na representação literária, encontramos vários exemplos da prática do silêncio sobre os crimes de máfia, ou seja, exemplos de omertà. No início da trama de Il giorno della civetta, apresenta-se ao leitor um cenário construído ao redor do silêncio sobre o assassinato de um homem enquanto subia as escadas de um ônibus. O único personagem a falar nesta cena, o cobrador, é oriundo de outra província, um lugar onde a omertà é desconhecida, fato que o narrador nos permite entrever: "Chi è? - domandò il bigliettaio indicando il morto. Nessuno rispose." (SCIASCIA, 1993, p. 10). O cobrador percebe uma modificação no hábito falastrão dos passageiros de sempre. Diante do defunto caído dentro do ônibus, todos se calam:

Il bigliettaio guardava il morto e poi i viaggiatori. C'erano anche donne sull'autobus, vecchie che ogni mattina portavano sacchi di tela bianca, pesantissimi, e ceste piene di uova; le loro vesti stingevano odore di trigonella, di stallatico, di legna bruciata; di solito lastimavano e imprecavano, ora stavano in silenzio, le facce come dissepolte da un silenzio di secoli. (SCIASCIA, 1993, p. 10)

O leitor é informado de que o cobrador é proveniente da província "boba" de Siracusa, não possuindo, por sua origem, "experiência em assassinatos". Por isso, fala quando deveria calar-se, ao contrário dos outros personagens presentes à cena do assassinato, todos sicilianos.

Depois de intimar algumas testemunhas do assassinato, todas elas presentes no momento dos disparos que atingiram o homem enquanto pegava o ônibus, um oficial do corpo dos carabinieri conclui "- Non vogliono parlare - intervenne il maresciallo - anche se li levano di mezzo uno dopo l'altro, non parlano: si contentano farsi ammazzare". (SCIASCIA, 1993, p. 19). Estamos diante da representação da prática cultural da omertà, em que as testemunhas abstêm-se de declarar o que testemunharam a fim de que o crime se resolva entre os que nele estão envolvidos, e não pelas leis do Estado. “ 'Questo è il punto' pensò il capitano 'su cui bisognerebbe far leva'. È inutile tentare di incastrare nel penale un uomo come costui: non ci saranno mai prove sufficienti, il silenzio degli onesti e dei disonesti lo proteggerà sempre." (SCIASCIA, 1993, p. 93). Nessa passagem, evidencia-se a maior preocupação de Sciascia: a prática da omertà permitindo a impunidade, fator preponderante para o imobilismo da sociedade siciliana, segundo sua análise. 
Em A ciascuno il suo, o protagonista da trama é um professor que decide investigar os assassinatos de duas figuras bastante conhecidas naquela comunidade: um farmacêutico e um advogado. Porém, o narrador informa ao leitor que "non c'era uno nel paese che non avesse già, per conto suo, segretamente, risolto o quasi il mistero; o che si ritenesse in possesso di una chiave per risolverlo." (SCIASCIA, 1988, p. 30). O alvo da omertà, nesta narrativa, não são os agentes da lei, mas um investigador amador e ingênuo, incapaz de perceber a lei do silêncio praticada por toda a sociedade à sua volta. Na trama, não faltam exemplos que reforçam o caráter de "impessoalidade diante da lei" como um hábito cultural. Em um interrogatório policial, a empregada da casa onde morava o farmacêutico sucumbe à revelação do que realmente sabe após passar um longo período na delegacia sendo interrogada. Repentinamente, a personagem se lembra de todas as informações requeridas durante horas pelo policial, numa clara demonstração de que a verdade, naquele contexto, não é desconhecida, mas ocultada, enfim um hábito:

'E come si chiama questa ragazza?' Risposta 'Non lo so' con le varianti 'Non la conosco, non l'ho mai vista, l'ho vista una sola volta e non la ricordo nemmeno' dalle 14:30 alle 19:15, ora in cui per improvviso rinverdire della memoria la cameriera ricordò il nome non solo, ma l'età, la strada, il numero civico, i parenti fino al quinto grado e una infinità di altre notizie relative alla ragazza in questione. (SCIASCIA, 1988, p. 25-26)

Para reforçar o hábito do silêncio, há nesta trama os cães que testemunham os assassinatos de seus donos. Os policiais tentam, em vão, fazer com que a matilha, que retornou sozinha e desacompanhada à cidade, os leve até o local onde as vítimas se encontram. "Ma i cani non se ne dettero intesi [...]" (SCIASCIA, 1988, p. 20). A sicilitudine personificada nos animais reforça a ideia de potência que a lei do silêncio possui naquele contexto, uma cultura arraigada e intransponível pela ótica do autor do romance.

Em Il contesto, vemos menos abundantes os exemplos do silêncio de cunho existencial, ou seja, enquanto sicilitudine, de modo que há um único personagem a procurar a verdade nesta trama: o inspetor Rogas, um agente da lei que, enquanto siciliano, apesar de conhecer a lei do silêncio, busca descobrir os mandantes dos assassinatos ocorridos na trama. Aqui encontramos a omertà praticada por interesse próprio, por figuras representantes do Estado. Nesta obra, é o poder legal que aparece corrompido, simbolicamente representando a máfia, ou melhor, a mafiosità del potere. Como não há a máfia nesta trama, mas percebemos a cultura do silêncio representada no comportamento de alguns personagens, compreendemos aqui a instrumentalização da omertà, uma vez que não é a sociedade que silencia sobre os crimes, porque nem mesmo os testemunham. Nesta narrativa, encontramos o contrário das outras analisadas anteriormente: aparecem testemunhas informando tudo o que supostamente sabem e o que viram, porém declarando falsos testemunhos.

O inspetor, protagonista da trama, é orientado por ordens superiores a deixar imexíveis as evidentes provas de incriminação dos culpados por uma série de assassinatos de magistrados, 
mas Rogas vai atrás justamente dessas provas para desvendar os crimes. Porém, não obterá sucesso. Logo percebe que são seus próprios superiores os interessados em uma investigação inconclusa e, consequentemente, sem punição:

Dentro il problema di una serie di crimini che per ufficio, per professione, si sentiva tenuto a risolvere, ad assicurarne l'autore alla legge se non alla giustizia, un altro ne era insorto, sommamente criminale nella specie, come crimine contemplato nei principi fondamentali dello Stato, ma da risolvere al di fuori del suo ufficio, contro il suo ufficio. In pratica, si trattava di difendere lo Stato contro coloro che lo rappresentavano, che lo detenevano. Lo Stato detenuto. E bisognava liberarlo. Ma era in detenzione anche lui: non poteva che tentare di aprire una crepa nel muro. (SCIASCIA, 1994, p. 82-83)

Existe uma linha gradativa na representação da lei do silêncio nessa trilogia de romances-ensaio, posto que, da primeira à última obra, a omertà é cada vez mais imperceptível, menos evidente, até se tornar a metáfora da corrupção, como no último livro da "trilogia". A prática se dilui em um comportamento cada vez menos relacionado à organização criminosa e cada vez mais identificado com uma postura individual, uma questão de caráter diante do poder. Para Puleio (2003, p. 61):

Nel Giorno della civetta, si assiste al trionfo della mafia in una dimensione regionale, vernacolare, in A ciascuno il suo, secondo anello di questa trilogia, al vernacolo è subentrata la lingua, la mafia è sistema di potere nazionale. (...) Nel Contesto, l'epilogo della trilogia, lo scrittore può asserire dovunque il potere è mafia: la dimensione siciliana è diventata specchio di un'antropologia universale del potere.

Os personagens que buscam alcançar a verdade sobre os crimes ocorridos nas tramas se deparam com uma delação impossível e tentam buscar, sozinhos, essas verdades impronunciáveis, que são os testemunhos que a omertà não permite serem dados. Esses personagens representam o próprio escritor, que buscou, enquanto intelectual, romper com a prática de uma lei à qual ele supostamente deveria obedecer, enquanto siciliano.

\section{Considerações finais}

Vimos que a prática da omertà, lei do silêncio de base cultural e com raízes identitárias sicilianas, era vista com desaprovação por Leonardo Sciascia, de acordo tanto com seu posicionamento sobre o assunto em ensaios quanto com evidências discursivas encontradas no corpus analisado: os romances policiais Il giorno della civetta, A ciascuno il suo e Il contesto. Para o escritor, a omertà apresentava duas implicações: contribuía para a máfia agir impunemente e colocava o siciliano na posição de protetor da organização criminosa.

Pode-se considerar o primeiro problema como de ordem política, uma vez que põe em xeque a eficiência e a honestidade dos agentes e órgãos públicos de segurança da Sicília. O 
segundo problema, consideramos ser de ordem histórica e identitária, dado que o siciliano, segundo análise de Sciascia, é condicionado historicamente a fechar-se em si mesmo, fazendo da sua família um microcosmo capaz resolver todos os conflitos cujas resoluções deveriam ser delegadas às instituições públicas.

Afirmamos anteriormente que o siciliano se acostumou a ver a máfia como o governo e que hábitos como a omertà, o familismo e a desconfiança em relação ao Estado oficial são suas marcas identitárias, apontadas por estudiosos da região. Embora compreenda a máfia como uma organizzazione per delinquere, defende Sciascia que, para o cidadão siciliano, a máfia é o Estado, a única ordem que conhece. Percebemos que Sciascia tenta desvincular a imagem do siciliano da faceta de cúmplice da máfia, relacionando a prática da omertà na sociedade siciliana a um hábito cultural vinculado à sicilitudine. Sua preocupação, assim, será com os inúmeros crimes sem castigo praticados pela organização criminosa, ou seja, um efeito da lei do silêncio. Corroboramos, então, a nossa hipótese de que, dentro da temática mafiosa, tanto em seus ensaios quanto em seus romances, o escopo de Leonardo Sciascia era a questão do silêncio sobre a máfia, suas prováveis causas e suas inconfundíveis consequências. Ele refuta a tese que defende a omertà como uma proibição em dar testemunhos sobre crimes e em delatar criminosos e crê na ideia de um desinteresse dos sicilianos em se envolver em assuntos que não são de seu interesse pessoal, ou ainda, envolver-se em assuntos em que não se reconhece uma transgressão da lei.

Com a publicação de Il giorno della civetta (1961), Sciascia propõe sua visão sobre a organização, aquela a qual crê ser a "verdadeira" e que assim será entendida, também, pelos críticos e pela sociedade italiana. Numa época em que todos os intelectuais silenciavam sobre o assunto e a máfia, na literatura, era representada de forma folclórica, Sciascia, então, é aquele que rompe o silêncio. Para ele, romper com a omertà é o mesmo que falar a verdade. E a verdade, nesse contexto, significa honestidade, compromisso e atitude, ao contrário do descompromisso, omissão e apatia, características às quais atribui aos seus conterrâneos. Para o escritor, há uma "essência mafiosa" em todo siciliano, que nada mais é que uma antropologia por meio da qual toda a sociedade se relacionará com a máfia, constatação que se revela incômoda para ele, uma vez que, dessa maneira, é atribuída a essa sociedade a função de protetora das atividades mafiosas. O grande problema, no entanto, não seria esse, mas o não entendimento dos sicilianos dessa relação de contiguidade mafiosa que a eles é atribuída, o que se revela um problema grave, pois à medida que silenciam a respeito da existência de uma organização criminosa, por não a reconhecerem como tal, fomenta-se não apenas o poder da máfia, mas também a mafiosità del potere. A verdade impronunciável para a maioria dos sicilianos, - posto que não reconhecida por alguns e inconveniente para outros - mas redentora para Leonardo Sciascia, será evidenciada pelo autor ao longo de suas publicações ensaísticas e literárias. A verdade a se reivindicar, no entanto, apenas será alcançada com a quebra do padrão, do valor, da tradição do silêncio. E ele realiza este movimento, tendo a coragem de pronunciar a verdade que, para um siciliano, seria impronunciável. 


\section{Referências bibliográficas}

BALDWIN, T. Leonardo Sciascia: l'uomo il citadino e lo scrittore. Lo Stato delle Cose: Pensiero Critico \& Scritture, set-ott 1998.

BARNI, R.; BONA, F. Em busca de um ethos siciliano. Itinerários, n. 43, p. 155-176, 2016.

FRANCESE, J.Leonardo Sciascia e la funzione sociale degli intellettuali. Firenze: Firenze University Press, 2012.

FRANCHETTI, L. Condizioni politiche e amministrative della Sicilia. Firenze: Tipografia di G. Barbèra, 1877.

LAMPEDUSA, G. T. O Gattopardo. Trad. Marina Colasanti. Rio de Janeiro: Record, 2007.

LORUSSO, P. Il ritorno al Sud di Saviano. La Stampa, 18 set. 2010. Disponível em: <http://www1. lastampa.it/redazione/cmsSezioni/cronache/201007articoli/56828girata.asp>. Acesso em: 22 ago 2020.

LUPO, S. História da máfia: as origens aos nossos dias. Trad. Álvaro Lorencini. São Paulo: Editora Unesp, 2002.

PITRÈ, G. Opere complete. Roma: Soc. Editrice del Libro Italiano, 1940.

PULEIO, B. I sentieri di Sciascia. Palermo: Kalós, 2003.

PUZO, M. Omertà. Trad. Sylvio Gonçalves. 2. ed. Rio de Janeiro: Record, 2000.

SCIASCIA, L. La Sicilia come metafora. Milano: Mondadori, 1979. . A ciascuno il suo. Milano: Adelphi, 1988.

. Il giorno della civetta. Milano: Adelphi, 1993.

. Il contesto. Milano: Adelphi, 1994.

. La mafia. In:___. Pirandello e la Sicilia. Milano: Adelphi, 1996. p. 191-211.

2016. . Sicilia e sicilitudine. In:___ La corda pazza: scrittori e cose della Sicilia. Milano: Adelphi, . A futura memoria: se la memoria ha un futuro. Milano: Adelphi, 2017.

Recebido em: 11/09/2020

Aprovado em: 13/11/2020 